\title{
Structure of the central nervous system of a juvenile acoel, Symsagittifera roscoffensis
}

\author{
Amandine Bery • Albert Cardona $•$ Pedro Martinez • \\ Volker Hartenstein
}

Received: 19 February 2010 / Accepted: 19 May 2010/Published online: 15 June 2010

(C) The Author(s) 2010. This article is published with open access at Springerlink.com

\begin{abstract}
The neuroarchitecture of Acoela has been at the center of morphological debates. Some authors, using immunochemical tools, suggest that the nervous system in Acoela is organized as a commissural brain that bears little resemblance to the central, ganglionic type brain of other flatworms, and bilaterians in general. Others, who used histological staining on paraffin sections, conclude that it is a compact structure (an endonal brain; e.g., Raikova 2004; von Graff 1891; Delage Arch Zool Exp Gén 4:109-144, 1886). To address this question with modern tools, we have obtained images from serial transmission electron micro-
\end{abstract}

Communicated by D.A. Weisblat

A. Bery $(\bowtie)$

Laboratoire de Développement, Evolution,

Plasticité du Système Nerveux,

CNRS Institut de Neurobiologie Alfred Fessard,

Bâtiment 33, Avenue de la Terrasse,

91198 Gif-sur-Yvette Cedex, France

e-mail: amandinebery@yahoo.fr

V. Hartenstein $(\bowtie)$

Department of Molecular, Cell and Developmental Biology,

Molecular Biology Institute, University of California,

Los Angeles,

Boyer Hall 559, 621 Charles E. Young Drive South,

Los Angeles, CA 90095, USA

e-mail: volkerh@mcdb.ucla.edu

\section{A. Cardona}

Institute of Neuroinformatics, Uni/ETH Zurich,

Winterthurerstrasse 190 Bau 55,

Zurich 8057, Switzerland

P. Martinez

Departament de Genètica, Universitat de Barcelona,

Av Diagonal, 645,

08028 Barcelona, Spain scopic sections of the entire hatchling of Symsagittifera roscoffensis. In addition, we obtained data from wholemounts of hatchlings labeled with markers for serotonin and tyrosinated tubulin. Our data show that the central nervous system of a juvenile $S$. roscoffensis consists of an anterior compact brain, formed by a dense, bilobed mass of neuronal cell bodies surrounding a central neuropile. The neuropile flanks the median statocyst and contains several types of neurites, classified according to their types of synaptic vesicles. The neuropile issues three pairs of nerve cords that run at different dorso-ventral positions along the whole length of the body. Neuronal cell bodies flank the cords, and neuromuscular synapses are abundant. The TEM analysis also reveals different classes of peripheral sensory neurons and provides valuable information about the spatial relationships between neurites and other cell types within the brain and nerve cords. We conclude that the acoel $S$. roscoffensis has a central brain that is comparable in size and architecture to the brain of other (rhabditophoran) flatworms.

Keywords Acoel · Central nervous system · Nerve cords . Nerve net · Sensory receptors $\cdot$ Transmission electronic microscopy $\cdot 3 \mathrm{D}$ modeling software

\section{Introduction}

Acoela are small aquatic (mostly marine) worms characterized by the absence of body cavities, a proper gut, protonephridia, and oviducts. (von Graff 1891; Bresslau 1909; Hyman 1951; Bush 1981; Rieger et al. 1991; Hooge and Tyler 2003; Achatz 2005). Morphological studies based on the male copulatory organ, the sperm structure, and the body wall musculature (Hooge 2001; Kostenko and 
Mankaev 1990) have distinguished 21 families and about 380 species (Hooge and Tyler 2006) to date. Traditionally, Acoela were placed among the Platyhelminthes, but recent molecular phylogenetic studies suggest that this taxon is the sister group of the remaining bilaterians (Ruiz-Trillo et al. 1999, 2004; Halanych 2004; Sempere et al. 2007; Wallberg et al. 2007; Philippe et al. 2007; Hejnol et al. 2009). In addition, according to some authors, morphological studies using characters such as ciliary rootlets, epidermis, and brain, also favor the separation of the Acoela from the remainder of the platyhelminthes ("Rhabditophora") and place the Acoela as the first offshot of the bilaterian animals (Haszprunar 1996; Kotikova and Raikova 2008).

If Acoela are the earliest member of Bilateria, this placement would have profound implications for the theory of bilaterian origins (Salvini-Plawen 1978; Holland 2003; Baguñà and Riutort 2004; Hejnol and Martindale 2008). This scenario, in fact, suggests the possibility that the common bilaterian ancestor might have had the structural complexity of a modern acoel, underlining the importance of understanding in detail the structural and functional characteristics of the acoel bauplan. In this paper we present the results of our analysis of the nervous system of the acoel Symsagittifera roscoffensis.

The nervous system of Acoela has so far been studied mainly by immuno-histochemical methods (i.e., antibodies against different neurotransmitters; Raikova 2004; Reuter et al. 1998; Kotikova and Raikova 2008; Gaerber et al. 2007), and ultrastructural approaches (Reisinger 1925; Ramachandra et al. 2000; Tyler 2001). Based on the immuno-histochemical markers (in particular, the expression of the transmitter serotonin), Raikova (2004) claimed that the central nervous system (CNS) of Acoela is a commissural brain (i.e., a regular pattern of longitudinal nerve cords interconnected by transversal commissures). However, it is important to point out that such markers reveal only a very limited set of neurons, leaving a significant part of the nervous system unlabeled (Cebrià 2008; Grimmelikhuijzen et al. 2002). Using a different set of approaches involving the analysis of histological material and electron microscopy, other authors have demonstrated the presence of a central brain surrounding the statocyst in this group of animals (von Graff 1891; Delage 1886; Reisinger 1925; Ramachandra et al. 2000; Tyler 2001). In a detailed analysis, Delage (1886) showed that the CNS in adult and juvenile Convoluta (Symsagittifera) schultzii (Acoela, Sagittiferidae) appears to be formed by a bilobed mass of neuronal bodies with commissure and connective complexes. More recently, with the help of transmission electron microscopy, it has been possible to obtain a more detailed view of the constituent cells in two acoel species, Convoluta (Symsagittifera) psammophila and Otocelis rubropunctata (Acoela, Oticelididae) (Bedini and Lanfranchi 1991).
In spite of the use of different histological tools, it has been impossible to define so far, with cellular resolution, the fine structure of any acoel nervous system. To tackle this problem, we have started to undertake a thorough investigation of the nervous system of the $S$. roscoffensis hatchling. We use this species as an experimental system due to the fact that we have access to all developmental stages throughout much of the year (Keeble 1910). The use of antibody markers and of serial transmission electron microscopy sections of the complete animal, plus new 3D modeling software (TrakEM2) reveals that $S$. roscoffensis (and probably most acoels) have a brain containing a "central mass" of neurons that gives rise to three pairs of nerve cords that extend along the whole body length. We here provide a first description of ultrastructural details of the brain, nerve cords and peripheral nervous system of $S$. roscoffensis.

\section{Materials and methods}

\section{Animals}

Egg clusters were obtained from cultures of adult specimens collected in Brittany (France), near the Station Biologique de Roscoff. They were shipped to Barcelona and then stored at $15^{\circ} \mathrm{C}$ in plastic dishes filled with artificial seawater (ASW). ASW salinity was adjusted to the levels of the seawater around Roscoff. 50-W fluorescent tubes provided illumination and the animals were kept in a cycle of $12 \mathrm{~h}$ light and $12 \mathrm{~h}$ darkness in an environmental chamber, model SANYO MLR-350. Hatchlings were less than 3 days old when fixed. All hatchlings used in this paper were collected in 2006 and 2007.

Immunocythochemistry

\section{Anti-acetyl tyrosine tubulin}

The antibody reacts against tubulin's C-terminal tyrosine, an epitope that is present in many metazoan neurons and cilia. The ubiquity of this epitope allows detecting more neuron than when using any other neuronal marker.

Specimens were fixed in $4 \%$ paraformaldehyde (PFA) (made in $1 \times$ phosphate-buffered saline; PBS) for $1 \mathrm{~h}$ at $4^{\circ} \mathrm{C}$. After several washes in $1 \times$ PBS, they were stored in a solution of $1 \times \mathrm{PBS}, 0.1 \%$ sodium acid at $4{ }^{\circ} \mathrm{C}$ until use. After one wash in $1 \times \mathrm{PBS} / 0.1 \%$ TritonX-100 (PBT), specimens were blocked in $3 \% \mathrm{NGS} / \mathrm{PBT}$ for $1 \mathrm{~h}$ at room temperature (RT). Then they were incubated with a mouse anti-acetyl tyrosine tubulin (anti-TyrTub) antiserum (Sigma), at 1:100 dilution overnight at $4{ }^{\circ} \mathrm{C}$. Then specimens were washed several times in PBT and blocked in $3 \% \mathrm{NGS} / \mathrm{PBT}$ 
for $1 \mathrm{~h}$ at RT. Thereafter, specimens were incubated for $2 \mathrm{~h}$ with the secondary antibody, fluorescein isothiocyanate (FITC)-labeled anti-mouse immunoserum (Sigma; dilution 1:100). Finally, and after several washes in PBS, specimens were mounted in Vectashield media (Vector) and examined with an inverted confocal SPII Leica microscope. Image analysis was carried out using the software package: Leica Confocal Software.

Some samples were contrasted with phalloidin after the anti-TyrTub immunochemistry. Staining with Alexa Fluor 568-phalloidin (Molecular Probes, dilution 1:70) was performed for $1 \mathrm{~h}$ at RT. Following the removal of the phalloidin solution and two washes in $1 \times$ PBS, staining of cell nuclei was carried out by incubating the samples in DAPI (4', 6-diamino-phenyin-dole, dilactate; SigmaAldrich, Steinheim, Germany).

\section{Anti-serotonin}

This antibody specifically recognizes a monoamine neurotransmitter (5-hydroxytryptamine, or 5-HT) that is synthesized in serotonergic neurons. The anti-5-HT staining method has been widely used to reveal the overall structure of the nervous system in Acoela (Raikova 2004). Specimens were fixed in 4\% PFA (made in $1 \times \mathrm{PBS}$ ) for $1 \mathrm{~h}$ at $4^{\circ} \mathrm{C}$. After several washes in $1 \times \mathrm{PBS}$, they were dehydrated through a methanol series and stored in $100 \%$ methanol at $-20^{\circ} \mathrm{C}$ until use. After rehydration and several washes in $1 \times \mathrm{PBS} / 0.2 \%$ TritonX-100, specimens were blocked in $1 \times \mathrm{PBS} / 0.2 \%$ TritonX-100/2\%BSA for $1 \mathrm{~h}$ at RT. Then they were incubated overnight at $4^{\circ} \mathrm{C}$ with rabbit anti-serotonin antibody (Sigma) at 1:500 dilution. The specimens were subsequently washed several times in $1 \times \mathrm{PBS} / 0.2 \%$ TritonX-100 and later incubated for $1 \mathrm{~h}$ with the secondary antibody FITC-labeled anti-rabbit immunoserum (Sigma; dilution 1: 200). After several final washes, specimens were mounted in Fluoromount media (SouthernBiotech) and examined with an inverted confocal SPII Leica microscope. Image analysis was carried out using the software package: Leica Confocal Software.

\section{Transmission electronic microscopy}

The hatchlings were first relaxed with a solution of $7.14 \%$ $\mathrm{MgCl}_{2}$ (made in $\mathrm{ASW}$ ) for $5 \mathrm{~min}$ at RT. Then they were prefixed for $24 \mathrm{~h}$ at $4{ }^{\circ} \mathrm{C}$ in a solution of $4 \%$ paraformaldehyde and $2.5 \%$ glutaraldehyde, made in a phosphate buffer $0.1 \mathrm{M} \mathrm{pH}$ 7.3. After several washes in phosphate

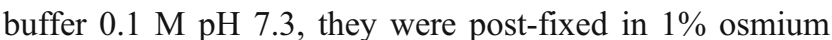
tetraoxide (made in phosphate buffer $0.1 \mathrm{M} \mathrm{pH} \mathrm{7.3)} \mathrm{for} 1 \mathrm{~h}$ at $4^{\circ} \mathrm{C}$. Specimens were later washed several times in distilled water. Finally they were dehydrated through an acetone series at $4^{\circ} \mathrm{C}$. These animals were embedded in Spurr resin. Transverse ultrathin sections of 60-70 nm thickness were produced in an Ultracut E ultramicrotome (Reichert-Jung) and collected on formvar-coated copper slot grids. The grids were stained with saturated uranyl acetate for $30 \mathrm{~min}$ at $37^{\circ} \mathrm{C}$, followed by the incubation in Reynolds lead citrate for $3 \mathrm{~min}$. The entire body of the hatchling was sectioned. Two to three ultrathin sections are cut every $1 \mu \mathrm{m}$ along the first $40 \mu \mathrm{m}$ of the animal's body. From here to the posterior end of the animal, the ultrathin sections were cut every $2 \mu \mathrm{m}$. The sections were examined with a transmission electron microscope (JEOL 100CX operating at $80 \mathrm{kV}$ ). Pictures were taken on type 4489 EM film (Kodak). As pictures were taken at high magnification, every section is represented, on average, by 30 negatives. The negatives were subsequently digitalized using a scanner HP Scanjet 7400c with the software Epson Perfection 4990 Photo.

\section{D modeling}

Two digital 3D models of the nervous system were produced: one from confocal stacks and the other from transmission electronic microscopy (TEM) serial sections. The first model was generated using the software TrakEM 2.0 (Albert Cardona; UCLA; with an Image J plug-in for three-dimensional modeling, see http:/www. ini.uzh.ch/ acardona/trakem2.html). The axonal processes, the sensory neurons, the nerve cords, and the central nervous system, which were revealed by the anti-tyrosin tubulin antibody, were outlined using the modeling functions. The traces were rendered in the program to generate a 3D model of the hatchling's nervous system. A second model, based on serial transmission electron microscope sections of $S$. roscoffensis, was generated using the same software. First, the 30 negatives representing each given section were "stitched" electronically into a montage. Subsequently, montages of 73 sections were aligned and combined into a "stack". Using the various modeling functions offered by TrakEM2, ciliary receptors, neuropile, and axon bundles were segmented, after which they could be displayed as a 3D digital model. Note that, given the relatively large gaps between adjacent sections, counts of individual cells (in particular sensory receptors) are not particularly accurate, given that the size of the ciliated apical pole of these cells is smaller than the average interval between sections. However, counts of all classes of receptors are affected by this shortcoming equally, so that our conclusions regarding (approximate) relative frequency of different sensory cells should be realistic. 


\section{Results}

The pattern of the brain neuropile and nerve cords

Hatchlings of $S$. roscoffensis have an ellipsoid shape with an average length of $200 \mu \mathrm{m}$ and an average width of $100 \mu \mathrm{m}$ (Fig. 1a, b). The body wall is formed by ciliated epidermal cells connected by septate junctions (Fig. 1b-d), and several layers of subepidermal muscle fibers (Fig. 1e). A basement membrane separating epidermis from muscle is lacking; as a result, nuclei and cell bodies of many epidermal cells are sunken below the muscle layer
(Fig. 1c; Reuter and Halton 2001), although in some cases, nuclei occupy a position peripheral to the musculature (Fig. 1e). At the anterior tip of the body, the frontal organ, a conglomerate of glands, opens through a circular pore (Fig. 1f). Numerous other gland cells are scattered throughout the epidermis. The interior of the hatchling is filled with the digestive syncytium (Fig. 1a, b, h) and the central nervous system (Fig. 1b). At about the middle of the hatchling's body length, a circular opening in the ventral epidermis forms the mouth (MO in Fig. 1). Hatchlings of $S$. roscoffensis lack a proper innervated pharynx (see Hooge and Tyler 2006; Todt 2008), a reproductive apparatus, and
Fig. 1 Major cell types and tissues of hatchling of $S$. roscoffensis. a Whole mount of live hatchling. Landmark structures include statocyst (st), brain (clear area surrounding statocyst; $b r$ ), apical complex of gland necks $(g l)$, and digestive syncytium (sc). Bar $20 \mu \mathrm{m}$. b. Low magnification view of cross-section of hatchling at level of statocyst (st), showing ciliated epidermis $(e p)$, brain (shaded purple; $b r$ ) with cortex $(c x)$ and neuropile (np), digestive syncytium $(s c)$, and ventral nerve cord $(v c)$. Bar $10 \mu \mathrm{m}$. c Cross-section of body wall. Epidermal cells $(e p)$ and muscle fibers $(m)$ are intermingled, without intervening basement memnbrane (note position of epidermal nucleus $(N)$ at a level basal of muscle fibers). Bar $2 \mu \mathrm{m}$. d High magnification of cell-cell contact between neighboring epidermal cells, showing septate junction $(s j)$. Bar $0.2 \mu \mathrm{m}$. e Cross-section of body wall, showing cell body of muscle cell $(\mathrm{ms})$ and transverse (circular) muscle process $(\mathrm{mp})$ containing myofilaments. Bar $2 \mu \mathrm{m}$. f Cross-section of the frontal organ $(f o)$, an apical pore surrounded by the necks of several glands $(g l)$. Bar $2 \mu \mathrm{m}$. $\mathbf{g}$ Cross-section of central brain, showing wall of statocyst $(s t)$, neuropile, and adjacent eye (ey). Visible is profile of pigment cell $(p c)$ and two receptor cells (pPr1, ppr2). Bar $5 \mu \mathrm{m}$.

h Cross-section of ventral body wall, showing mouth opening $(m o)$ and digestive syncytium (sc). Bar $2 \mu \mathrm{m}$

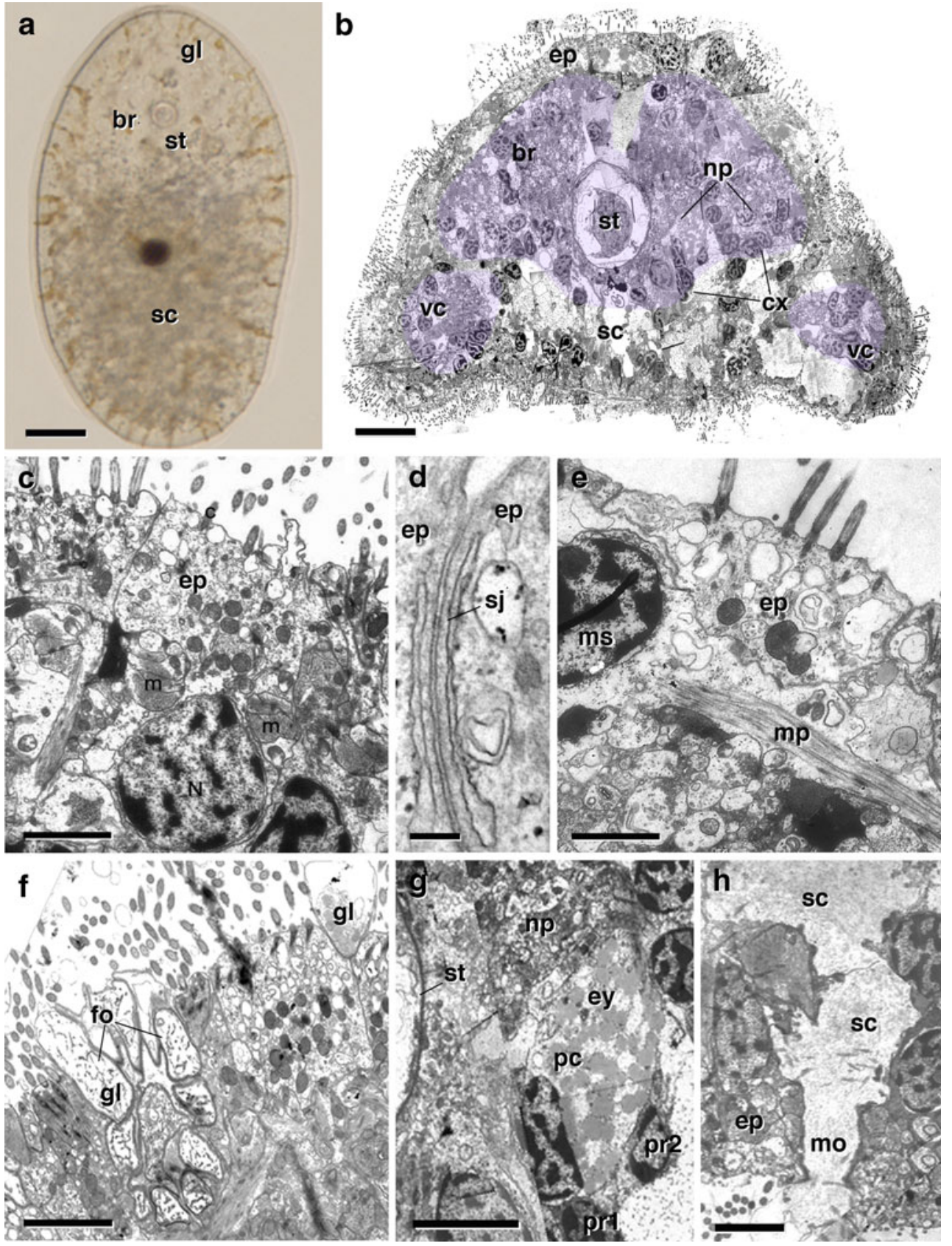


the sagittocysts, needle-shaped extrusomes which are characteristic for adults of the family Sagittiferidae.

Most of the anterior one third of the hatchling is filled with the brain, which consists of a peripheral layer of neuronal cell bodies (cortex) enclosing the central neuropile surrounding the statocyst (br, np, and st in Fig. 1b). The brain surrounds the unpaired statocyst and contains a bilateral pair of ocelli (Fig. 1g). Numerous muscle fibers and glands pass through the brain. Three pairs of longitudinal nerve cords that carry axons to and from the brain run along the whole length of the animal (Fig. 2). We distinguish a pair of ventral cords, and dorso-lateral cords (dlc), dorso-medial cords $(\mathrm{dmc})$. The nerve cords are crossconnected by a relatively invariant set of commissures. Sensory neurons, as well as axons leaving or entering into the nerve cords, form a peripheral nerve plexus.

The brain neuropile comprises two bilateral, roughly triangular domains that flank the statocyst and are linked by three commissures (Fig. 2a, c, g). From anterior to posterior, we distinguish commissures $\mathrm{c} 1, \mathrm{c} 2$ and $\mathrm{c} 3$. $\mathrm{C} 1$ and $\mathrm{c} 2$ cross-anterior and posterior of the statocyst, respectively; c3 interconnects the posterior tips of the neuropile. The ventral longitudinal nerve cords enter the brain at the level of commissure c1 (Fig. 2b); the dlc at

Fig. 2 Nervous system of hatchling of S. roscoffensis. a-f show Z projections of confocal stacks of whole mounts of specimens stained with different antibody markers; $G$ depicts 3D digital model reconstructed from confocal stacks of whole mounts of specimens stained with anti-TyrTub. In all panels, anterior is to the top. a-c Labeling with anti-TyrTub visualizes cilia, cell outlines, and neurites. a $\mathrm{Z}$ projection of sections though dorsal medial of specimen, outlining the brain $(b r)$ with statocyst $(s t)$, dorsomedial and dorso-lateral nerve cords $(d m c, d l c)$, and three commissures $(c 1, c 2, c 3)$. Bar $20 \mu \mathrm{m}$. b View of ventral half of body with ventral nerve cord and most anteroventral commissure $(c 1)$. Bar $20 \mu \mathrm{m}$. Inset in b shows Z-projection of posterior-right quadrant of hatchling that includes sections of the ventral and dorso-lateral cord, illustrating the transverse anastomeses between these cords (yellow arrowheads). c High magnification of brain, showing neuropile (np) surrounding statocyst (st). Bar $10 \mu \mathrm{m}$. d High magnification view of body wall of specimen labeled with phalloidin (muscles fibers in red), anti-TyrTub (neurites of nerve cord $(n c)$ and cilia (ci) in green) and DAPI (nuclei, blue). Nerve cords extend basal of the muscular layer; individual neurites leaving/ entering the cords intermingle with muscle fibers and reach the epidermis (arrow). Bar $10 \mu \mathrm{m}$. e, f Whole-mount juvenile specimen stained with anti-5-HT. Panel e shows $Z$ projection of confocal sections of dorsal body half; $F$ depicts ventral body half. Each one of the nerve cords $(d m c, d l c, v c)$, as well as several commissural tracts, contain anti-5-HT-positive axons. Staining is punctate, reflecting localization of serotonin in vesicles along nerve fibers. Only few cell bodies of serotonergic neurons are clearly visible, mostly anterior of the brain; examples are pointed out by yellow arrowheads in magnified inset of F. Bars $20 \mu \mathrm{m}$. g Digital 3D reconstruction of the hatchling's nervous system; dorsal view (left) and ventral view (right). Brain (br, orange), dorso-medial nerve cord ( $d m c$, dark blue), dorsolateral nerve cord (dlc, sky blue), commissures (cl-c7, violet), mouth opening $(M o$, pink $)$, sensory cells $(S c, r e d)$. St statocyst, vc ventral nerve cord the level of c2; and the dmc at the level of c3 (Fig. 2a, c). Numerous thinner and shorter fiber bundles radiate out from the neuropile towards the epidermis at the anterior tip of the body (Fig. 2b).

The nerve cords extend posteriorly along the entire length of the body (Fig. 2a, c, g). Anteriorly, the cords are located deeper and appear thicker, possibly as a result of containing more fibers. Towards posteriorly, cords become thinner and come closer to the basal surface of the epidermis. Anteriorly at the level of the commissure c1,
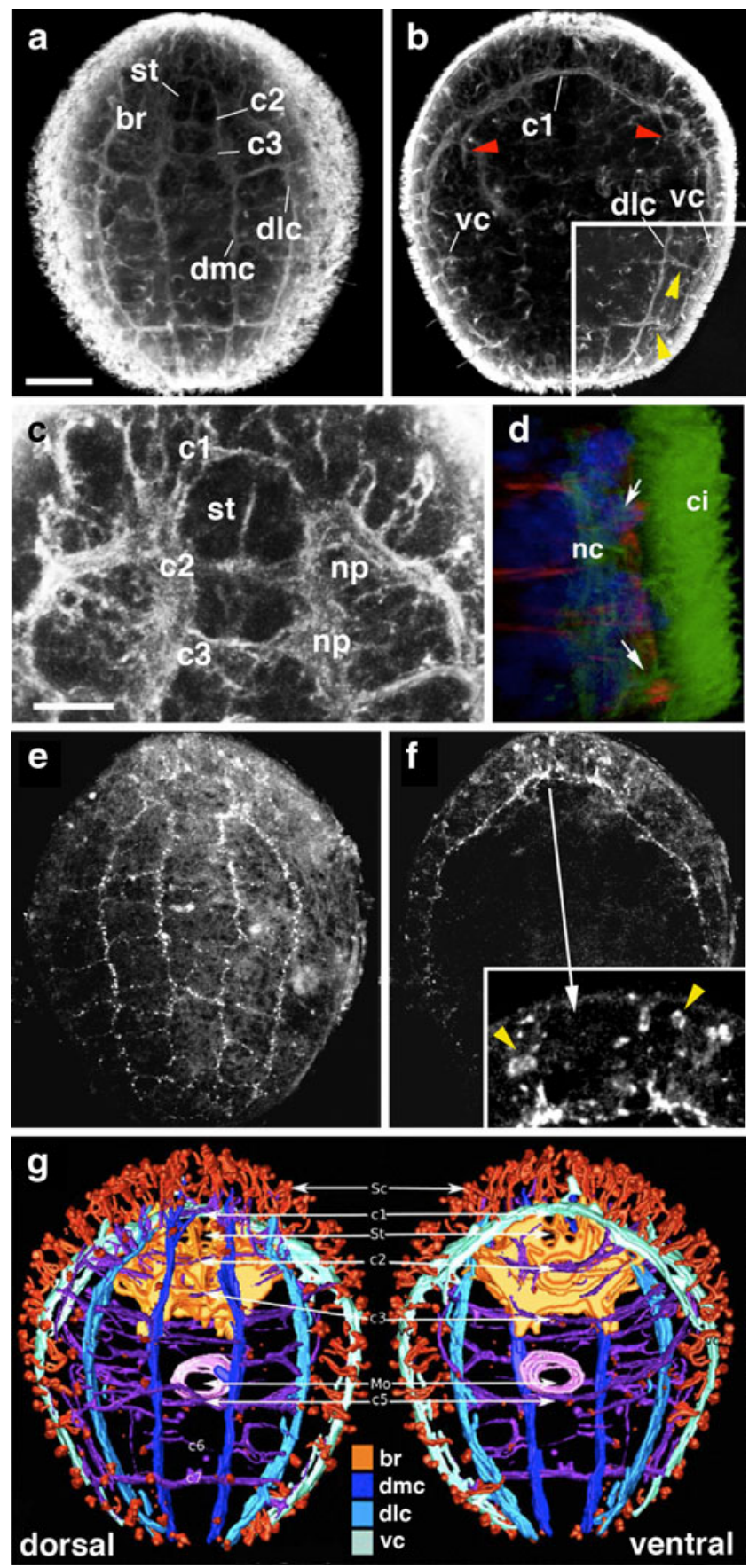
the ventral nerve cord is bifurcated, forming a short longitudinal branch that extends ventral of and parallel to the main cord until the level of commissure c3, where it ends blindly (Fig. 2b, g). In the trunk region, neighboring cords are interconnected by somewhat irregularly distributed anastomoses. In the specimen shown in Fig. 2a, b, four anastomoses connect the dorso-medial cords (commissures c4-c7); 4-5 anastomoses connect the dorso-medial with the dorso-lateral cords, and the dorso-lateral with the ventral cords (see inset of Fig. 2b). Neuronal cell bodies, preferentially clustered at the points of intersection of cords and anastomoses, flank the cords.

Anti-serotonin antibody reveals several neurons forming part of the brain and nerve cords. Labeling is found along the entire length of the ventral and both dorsal cords, the commissures surrounding the statocyst, and most transverse anastomoses of the trunk (Fig. 2e, f). Fibers and varicosities (presumably transmitter release sites; Falck 1962; Furness 1970) are strongly labeled, whereas neuronal cell bodies are difficult to discern. An exception are clustered cell bodies located in the epidermis at the anterior tip; these cells project (sensory) neurites towards the neuropile (Fig. 2f, inset).

Cells with structural characteristics of neoblasts can be seen associated with the brain and nerve cords. Neoblasts are pluripotent stem cells found in acoels and rhabditophoran flatworms (Gschwentner et al. 2001; Agata and Watanabe 1999; Ladurner et al. 2000). They can be recognized by a high nucleus-to-cytoplasm ratio, scarcity of cytoplasmic organelles, and chromatoid bodies (Gschwentner et al. 2001). In S. roscoffensis, most of these cells that exhibit characteristics of neoblasts occur in groups of two to three cells along the nerve cords (Fig. 3a, b). In the brain and epidermis, we observed a subset of these cells undergoing differentiation (Fig. 3c, e). In this population of cells, the cytoplasm of the cell sends long processes filled with microtubules and vesicles in-between the surrounding neuronal somata or epidermal cells (Fig. 3d).

\section{Ultrastructure of the brain}

The brain cortex contains approximately 700 cells and forms a thin layer of 1-2 cell diameter thickness around most parts of the neuropile (Figs. 1d, 4a). Cells include central neurons, sensory neurons with peripheral dendrites, the ocelli (containing a total of eight cells: three sensory cells and one pigment cell for each ocellus), and the statocyst (three cells: two parietal cells and the lithocyte). Both multipolar neurons and unipolar neurons can be frequently observed (Fig. 4b, c). Gland cells are also closely associated with the brain cortex, and thin gland cell processes occasionally run through the neuropile (Fig. 4d). Neuronal processes (neurites) fill the central neuropile. The diameter of sectioned neurites ranges from less than $0.1 \mu \mathrm{m}$ to approximately $1 \mu \mathrm{m}$ (Fig. $4 \mathrm{e}, \mathrm{f}$ ).
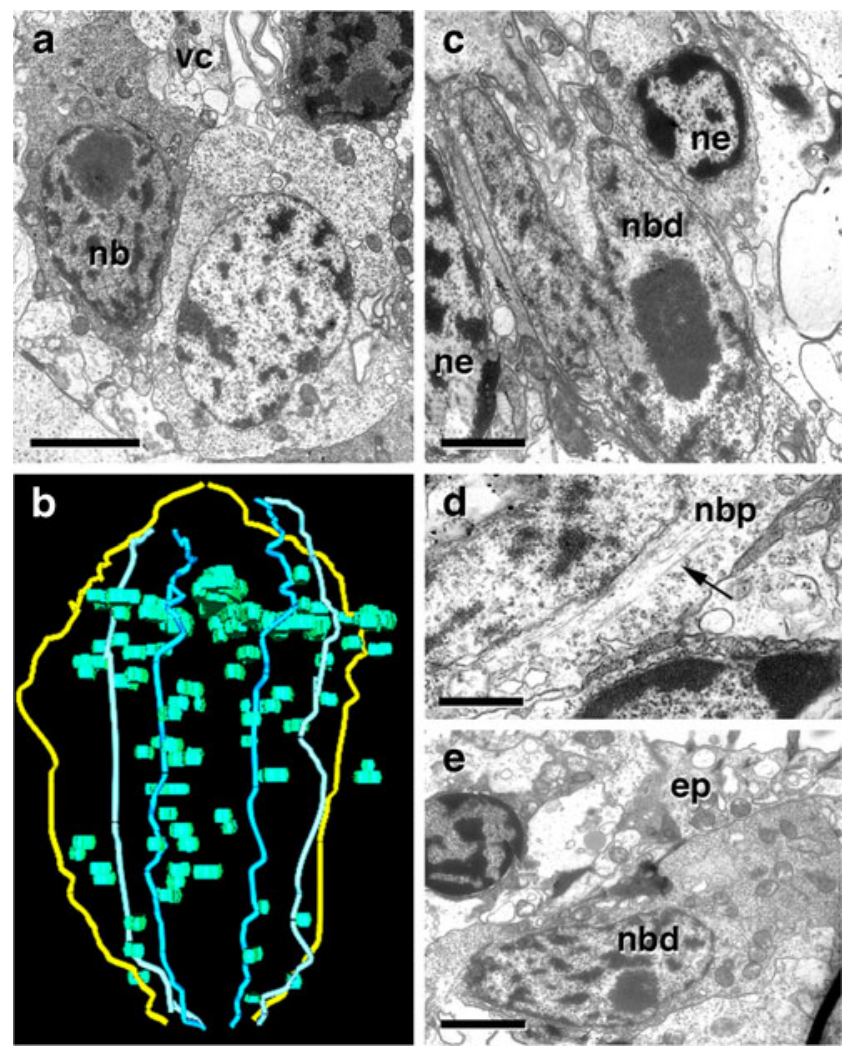

Fig. 3 Undifferentiated cells with neoblast-like characteristics. a Neoblast-like cell $(n b)$ adjacent to the ventral nerve cord $(v c)$. Bar $2 \mu \mathrm{m}$. b 3D reconstruction of juvenile $S$. roscoffensis showing distribution of neoblast-like cells (green) in relationship to the nerve cords. Dorsal view, anterior is to the top. The ventral nerve cords are rendered yellow, the dorsal pairs of nerve cords, $d m c$ and $d l c$, are in blue and cyan, respectively. c Neoblast-like cell $(n b d)$ intermingled with differentiated neurons (ne) in the cortex of the brain. Note elongated nucleus with large nucleolus. Bar $2 \mu \mathrm{m}$. d Detail of a process formed by neoblast-like cell $(n b p)$ associated with the brain cortex, containing bundles of microtubules (arrow). Bar $1 \mu \mathrm{m}$. e Neoblast-like cell (nbd) attached to the basal surface of the epidermis (ep). Bar $2 \mu \mathrm{m}$

Profiles falling within the upper part of this range $(0.4-1 \mu \mathrm{m})$ represent mostly presynaptic (axonal) terminal branches. Thus, in numerous instances, presynaptic specializations (synaptic vesicles, membrane densities; see below) could be observed in these large profiles (Fig. 5). We assume that the large number of thin $(0.1-0.2 \mu \mathrm{m})$ profiles belong to the highly branched postsynaptic (dendritic) branches, as has been described for other invertebrates (e.g., Drosophila; Cardona et al. 2010a, b; Fig. 4f). Figure 4f provides relative frequency of neurites with a given diameter, derived from counts of several hundred profiles contained within five adjacent sections of neuropile. Small-diameter profiles are predominant, very similar to what has been described for neuropile of other invertebrate species (Cardona et al. 2010a, b). On the other hand, the large "globular" axonal terminals (larger than $1.5 \mu \mathrm{m}$ ) that are characteristic for the brain of insects and other taxa are rare or absent in the acoel. 
Fig. 4 Architecture of the brain. a Low power electron micrograph of a cross-section through brain, showing central statocyst $(s t)$, neuropile $(n p)$, and cortex (cx). Bar $10 \mu \mathrm{m}$. b Section of neuron (ne) located at cortexneuropile boundary, showing three processes (arrows) emanating from soma. Bar $2 \mu \mathrm{m}$. c Unipolar neuron (ne) sending process into dorso-lateral nerve cord $(d l c)$. Bar $2 \mu \mathrm{m}$. d Group of elongated neurons (ne) and gland cell $(g l)$ in brain cortex. Bar $2 \mu \mathrm{m}$. e Section of part of brain neuropile exemplifying range of neurite diameters. Profiles of sectioned neurites are demarcated by red dots. Bar $1 \mu \mathrm{m}$. f Histogram showing distribution of neurite diameters in $S$. roscoffensis (left) and Drosophila melanogaster (right; from Cardona et al. 2010a, b). Numbers are based on measurements of several hundred profiles from adjacent sections of neuropile. Note in both species predominance of small profiles (less than $0.2 \mu \mathrm{m}$ )
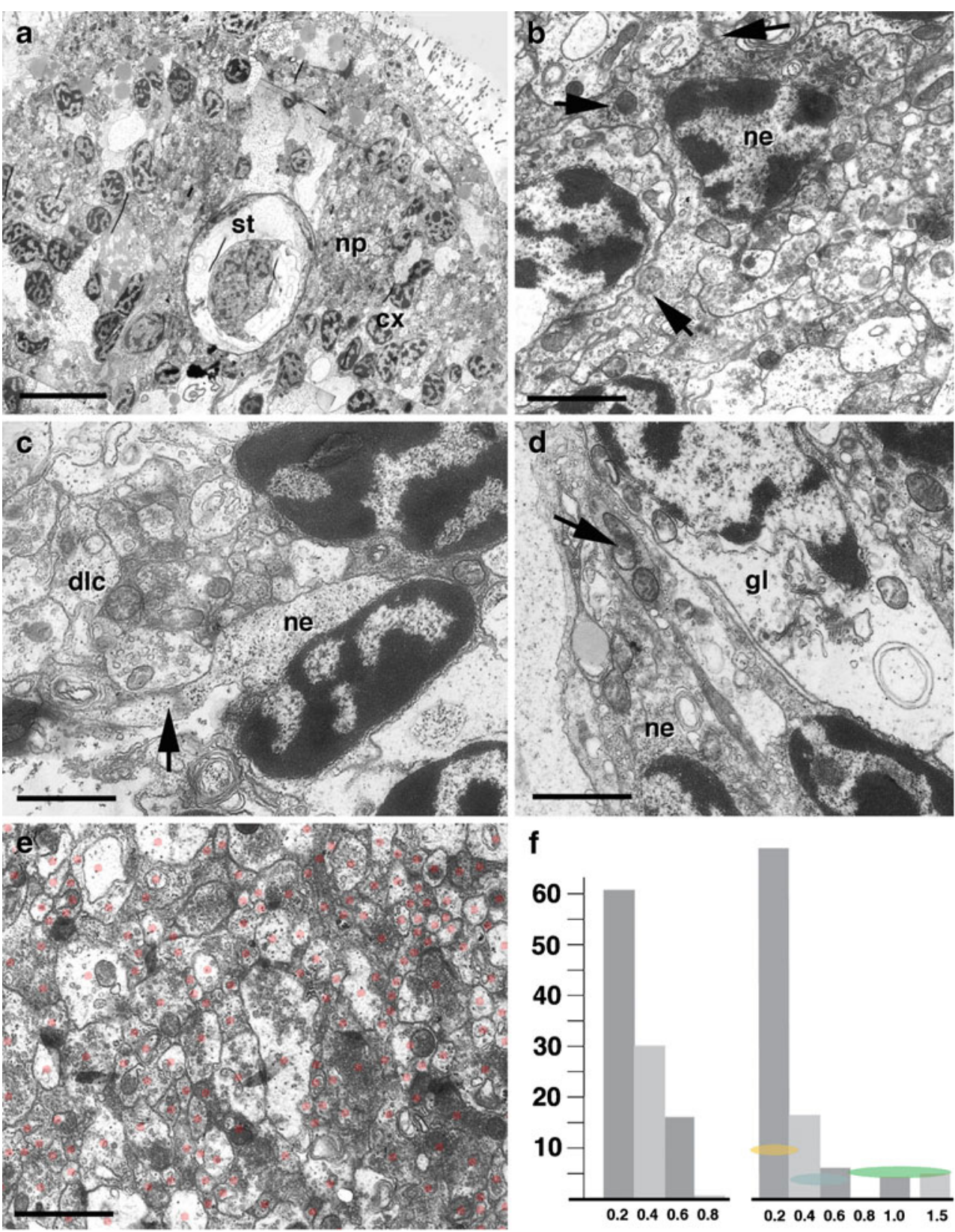

Characteristic sizes and shapes of synaptic vesicles allow one to define different classes of presynaptic neurites (for nomenclature, see Bedini and Lanfranchi 1991).

Type 1 neurites are characterized by the presence of small clear vesicles (sv) of 20-40 $\mathrm{nm}$ in diameter (Fig. 5a). This is the most abundant neurite type found in the neuropile. Small clear vesicles are mostly restricted to terminal neurite branches and synapses; in some cases, they are also found in neuronal somata (Fig. 5b).

Type 2 neurites are characterized by the presence of dense-core vesicles (dcv; Fig. 5a-d) with a diameter of 60 $120 \mathrm{~nm}$. These vesicles contain granular material surrounded by a clear halo. We could identify numerous cell bodies (Fig. 5b), among them sensory cells integrated within the epidermis (Fig. 5d), which also contained densecore vesicles. In some cases, both sv and dev can occur within the same type of neuron (Fig. 5c).

Type 3 neurites have $60-90 \mathrm{~nm}$ granules with homogenously dense content (Fig. 5e, f). These granules have the typical characteristics described for the peptide containing vesicles of neurosecretory cells (Bedini and Lanfranchi 1991). Aside from neurites, we could identify numerous cell bodies of neurosecretory cells in the cortex (Fig. 5e).

Numerous neurons were observed to house large vesicular organelles (lv) of different diameters and texture; an example is shown in Fig. 5a. The function of these organelles, which have also been described in the literature (e.g., Bedini and Lanfranchi 1991) is not clear. 
Fig. 5 Classification of neurites found in the central nervous system based on structure of vesicles. a Different types of vesicles encountered in the $S$. roscoffensis neuropile ( $d c v$ dense-core vesicles, $l v$ large vesicles, $s v$ small clear vesicles). Bar $0.5 \mu \mathrm{m}$. b Neuronal soma in brain cortex containining densecore vesicles and small clear vesicles. Bar $1 \mu \mathrm{m}$. c Neurite containing both small clear vesicles and dense-core vesicles. Bar $0.5 \mu \mathrm{m}$. d Intraepidermal sensory cell containing densecore vesicles. Bar $0.5 \mu \mathrm{m}$. e Neuronal soma (located near the ocellus) containing dense-core vesicle of neurosecretory type (nsv). Bar $1 \mu \mathrm{m}$. f Neurites in neuropile containing neurosecretory dense-core vesicles (nsv). Bar $1 \mu \mathrm{m}$. g, h Electrondense, glia-like cells forming lamellar processes (arrows) around groups of neurites in nerve cord (nc). Bar $2 \mu \mathrm{m}$

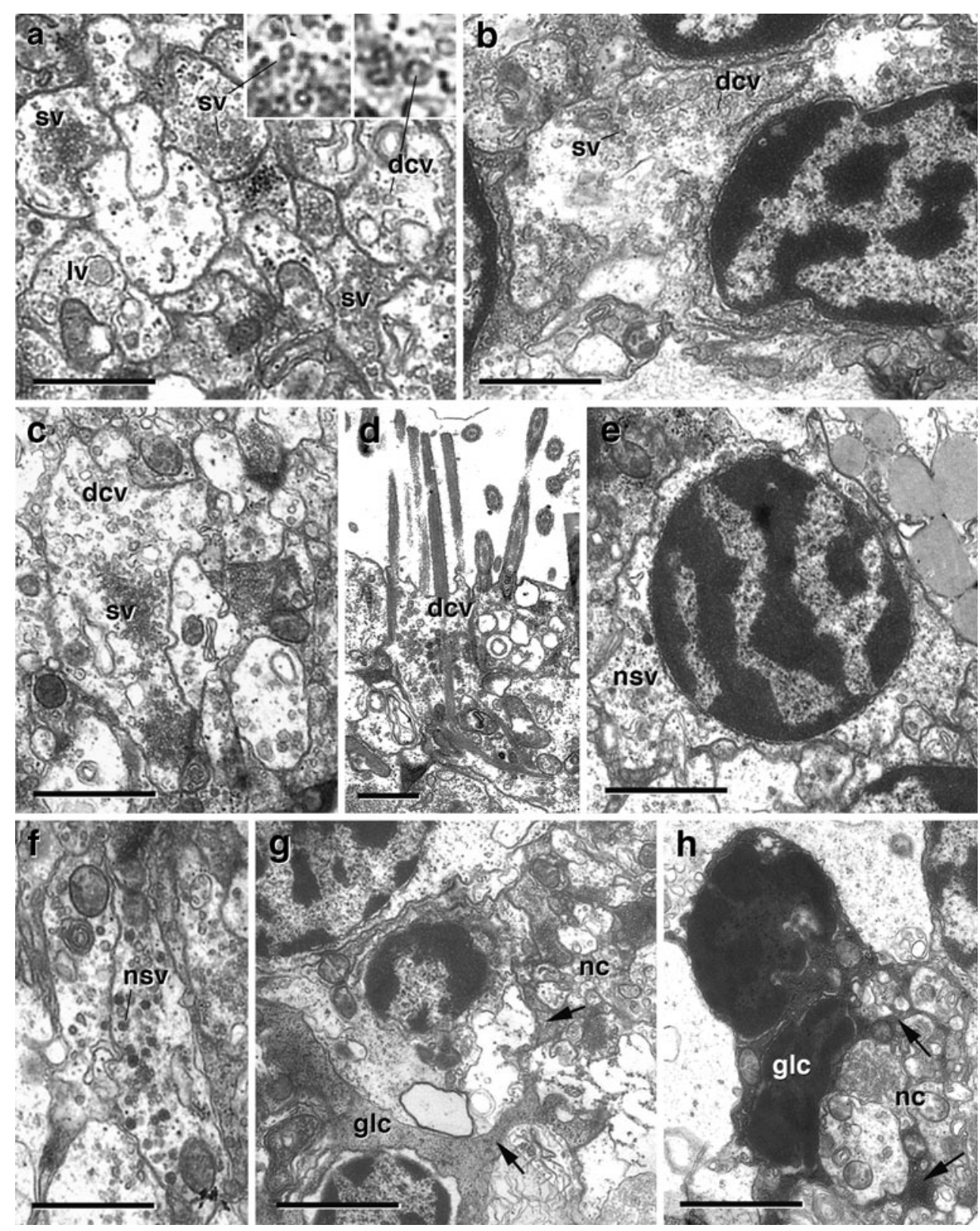

Aside from the profiles of typical cylindrical neurites, we observed irregularly shaped, highly electron-dense profiles that appear to correspond to lamellar, glia-like processes around groups of neurites (Fig. $5 \mathrm{~g}, \mathrm{~h}$ ). They occurred in the central neuropile and nerve cords. The cell bodies associated with these irregular profiles are electron-dense, often with hyper-dense nuclei filling almost the entire volume of the cell (Fig. 5h). Without additional markers it is difficult to clearly interpret this cell type. In several instances (e.g., Fig. 5h), cell bodies of these lamellated cells resembled apoptotic neuronal somata (see, for example, Fig. $3 \mathrm{~g}$ in Larsen et al. 2009, illustrating apoptotic neurons in Drosophila larvae). More detailed studies and the use of markers for apoptosis will be required to get a clearer picture regarding the nature of the "glia-like cells" we describe here.
Neurite profiles containing vesicles in conjunction with membrane densities can be identified as synapses. As described for most animals, in particular vertebrates (Colonnier 1968; Peter 2008), the S. roscoffensis neuropile contains symmetric and asymmetric synapses. Asymmetric synapses (Fig. 6a) are characterized by clusters of small and/or dense-core vesicles in the presynaptic element. The presynaptic membrane is thicker and denser than the postsynaptic membrane and often has a specialization called the synaptic ribbon (Fig. 6a, arrow). The synaptic cleft measures about $20 \mathrm{~nm}$. Symmetric synapses (Fig. 6b, arrowhead) are characterized by pre-and postsynaptic membranes of equal thickness and density. They typically contain dense-core vesicles, as shown in Fig. 6b, and less frequently small vesicles. In many cases, synapses are 


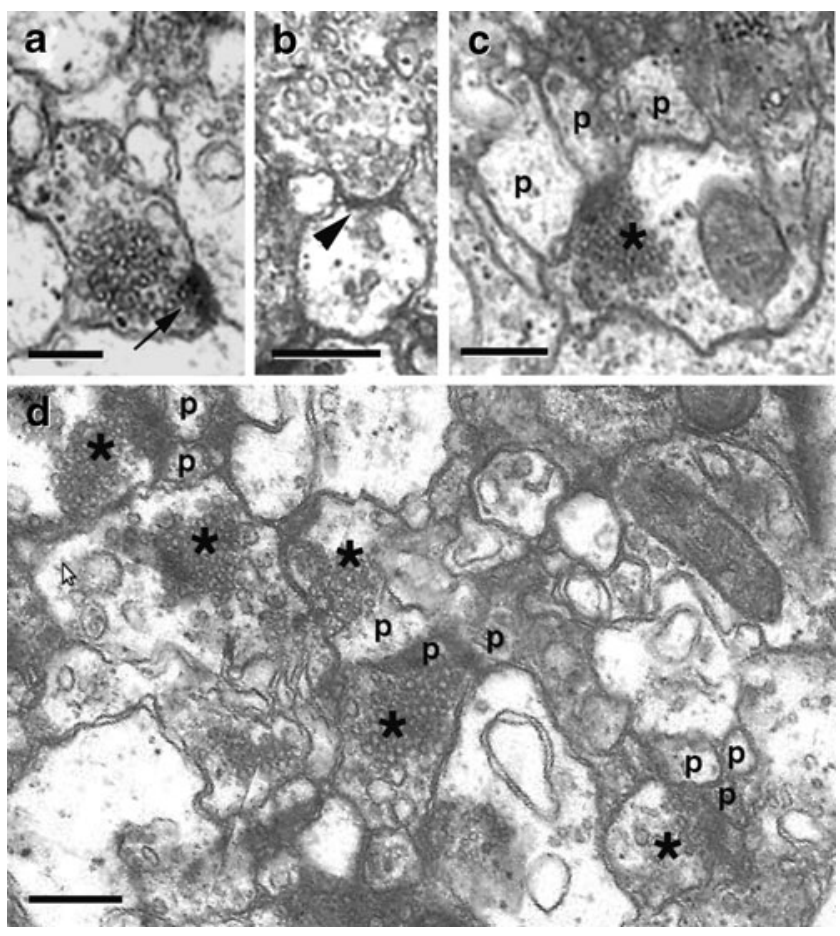

Fig. 6 Structure of synapses. a Asymmetric synapse showing small clear vesicles and pronounced synaptic ribbon (arrow). b Symmetric synapse containing dense-core vesicles and irregular vesicular structures. c Polyadic synapse. Large presynaptic profile (asterisk) contacts two small postsynaptic profiles $(p)$. d Cluster of polyadic synapses. Multiple presynaptic (asterisk) and postsynaptic $(p)$ profiles form dense aggregates. Bars in a-e: $0.2 \mu \mathrm{m}$

polyadic. Thus, possibly as a simple result of its larger diameter, one presynaptic element contacts two or more postsynaptic elements (Fig. 6c, d).

Although the method of sectioning did not allow reconstruct the three-dimensional architecture of terminal neurites in the neuropile, it is clear that many synapses are of the "en passant" type. Thus, terminal axonal branches form multiple swellings ("boutons" or "varicosities") along their path which are filled with mitochondria and carry the presynaptic sites.

Ultrastructure of the nerve cords, peripheral nerve net and sensory neurons

The nerve cords are formed by axons of neurons located in the brain. Figure $7 \mathrm{a}$ shows examples of neuronal cell bodies, located in the posterior cortex behind the statocyst, that give off branches towards the lateral nerve cord. In addition, neuronal somata are scattered along the entire length of the cords (Fig. 4c, 7b), specifically at the junctions with commissures. Electron-dense processes of glia-like cells form partial sheaths around and within the cords (Fig. 7b). At anterior levels, the cords contain in the order of $50-100$ neurites formed by neurons in the brain, as well as others grouped alongside the cords; towards the posterior tip of the body, the number of neurites declines to 15-30 (Fig. 7c, d). As in the brain neuropile, neurite shapes are irregular. Bundles of equally sized, microtubule-filled axons which are characteristic of the brain and cords of higher animals (Peters et al. 1976; Cardona et al. 2010a, b) are strikingly absent. Aside from neurites, the processes of muscle cells and glands lie within the nerve cords (Fig. 7c, d). Muscle processes frequently contact or even transect the cords (Fig. 7e), and synapses between nerve fibers and muscles are numerous (Fig. 7d).

Labeling with anti-TyrTub suggests the presence of a peripheral network of fibers located between the nerve cords and the epidermis (Fig. 2a, b). This nerve net contains numerous transverse and longitudinal fibers that connect to cells, presumably the somata of sensory neurons, which are integrated in the epidermis. However, anti-tyrTub also labels the cytocortex of cells in general, so that it is not possible to reconstruct the exact pattern of the peripheral nerve net from confocal sections of tyrTub-labeled preparations. TEM reveals more detail about the nerve net. It consists of individual, scattered fibers or thin bundles (two to three profiles). Fibers range from 0.2 to $0.6 \mu \mathrm{m}$ in diameter. The same types of vesicles observed in the central neuropile (small, dense core, secretory) can be observed in peripheral fibers (Fig. 8a). In rhabditophoran flatworms, the peripheral nerve net is known to contain two components, a subepidermal and a submuscular one. This distinction is not meaningful in acoels, where the somata and processes of epidermal cells and muscle cells, in the absence of a basement membrane, are intermingled. Nevertheless, the nerve net has both superficial components, which are in direct contact with the basal membrane of the epidermis and sensory receptors (Fig. 8c), and deep components interspersed among muscle fibers (Fig. 8b). Synapses between neurites and neuritesmuscle processes occur frequently within the peripheral plexus (Fig. 8d).

Based on ultrastructural features like apical membrane specializations (cilium, collar) and rootlet apparatus, numerous different types of sensory receptor cells have been distinguished in rhabditophoran (Xylander et al. 1997) and acoel flatworms (Todt and Tyler 2007). There exist three major classes: monociliated receptors without a microvillar collar (type I; Bedini et al. 1973), monociliated receptors with collar (type II), multiciliated receptors (without collar). Each of these main classes contains further subtypes. Sensory receptor cells are found everywhere in the epidermis but are concentrated at the anterior end (around the opening of the frontal glands) and along the ventral nerve cord trunks. Typically, the cell bodies of receptor cells are integrated within the epidermal layer; often the cell body is sunken slightly underneath the level of surrounding 
Fig. 7 Structure of the longitudinal nerve cords. a Cluster of neuronal somata in the posterior brain cortex whose processes could be followed into the root of one of the nerve cords exiting the neuropile (np). Bar $2 \mu \mathrm{m}$. b Cross-section of dorso-lateral nerve cord at mid-body level. Note somata of neuron (ne) and glia-like cell $(\mathrm{glc})$ accompanying cord. Bar $2 \mu \mathrm{m}$. c Crosssection of ventral nerve cord $(v c)$ at posterior level. Processes of gland cells $(g l)$ and many muscle cells (arrowheads) surround the cord. Bar $0.5 \mu \mathrm{m}$. d Synapse between ventral nerve cord axon and muscle process (ms; arrow). Bar $0.5 \mu \mathrm{m}$. e Multiple synapses (arrows) between ventral cord axons $(v c)$ and muscle fibers $(\mathrm{ms})$. Bar $0.25 \mu \mathrm{m}$
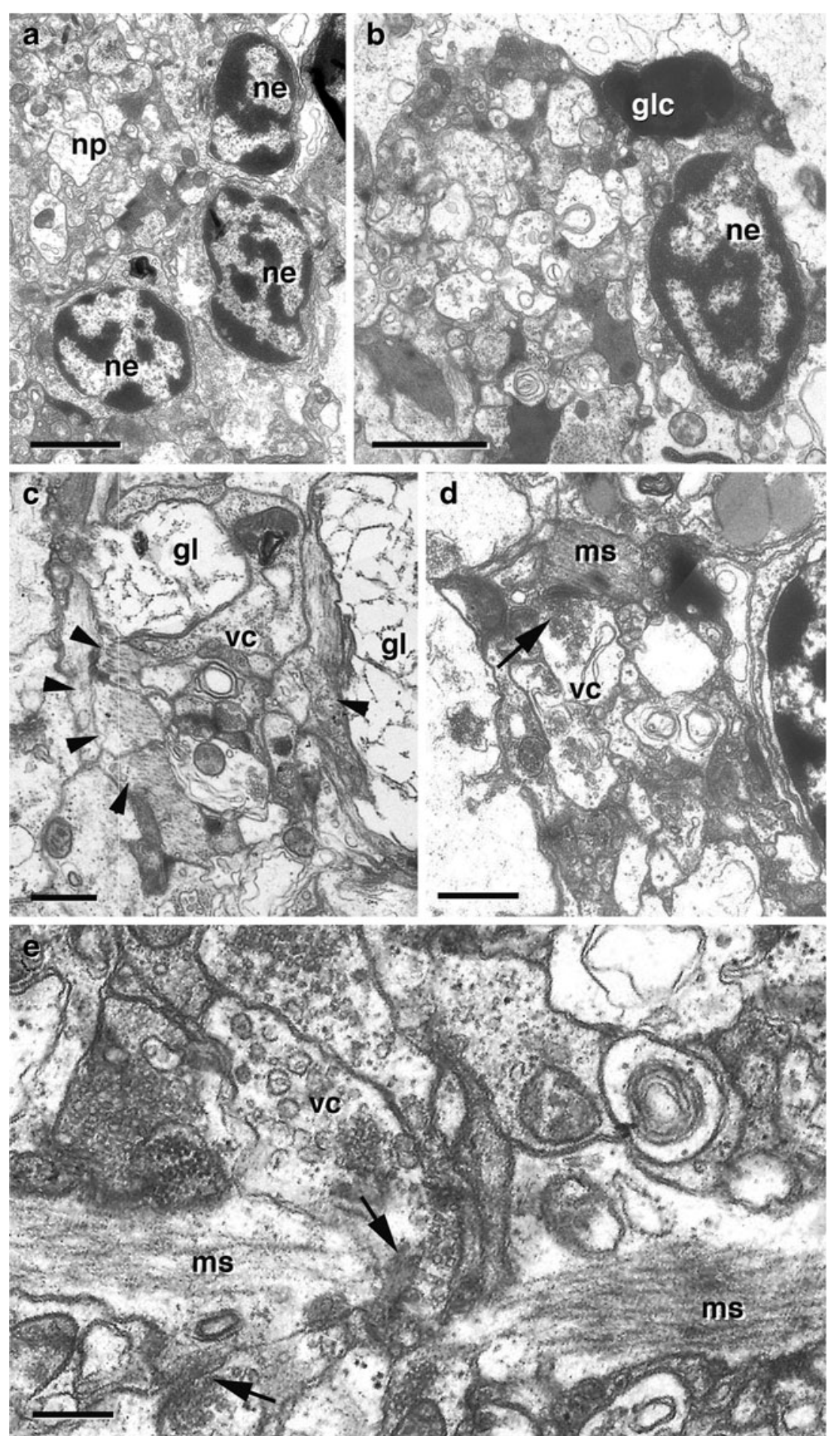

epidermal cells (Fig. 8,9c). Many receptor cells contain dense vesicles of the neurosecretoy type (Fig. 9a), suggesting that they produce peptides which are either released in a paracrine fashion, or synaptically stimulate nerve fibers or muscle processes. In hatchlings of $S$. roscoffensis, we encountered four types of monociliated receptors of the collared and non-collared type.
Non-collared (type I) receptors with a hollow ciliary rootlet containing a granulated core (Fig. 9a, b) have a central cilium that is anchored by a wide, hollow, striated rootlet containing a granulated core (Fig. 9a: cilium not shown on the panel). The receptor apex lies above the level of the surrounding cells. The core of the rootlet contains granulated material and is always associated with a mitochondrion. Dense core 


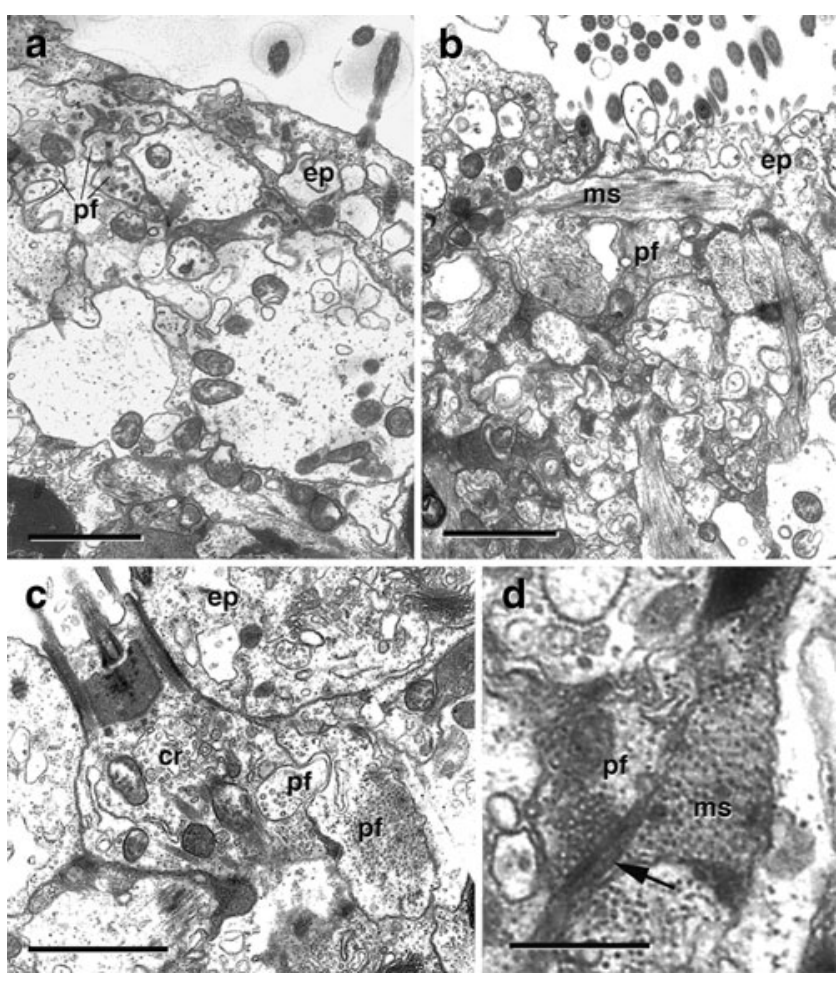

Fig. 8 Structure of the peripheral nerve plexus. a Group of peripheral neurites $(p f)$ with neurosecretory dense-core vesicles form part of a superficial plexus at the basal surface of the epidermis (ep). Bar $1 \mu \mathrm{m}$. b Peripheral fibers $(p f)$ interspersed with muscle fibers $(\mathrm{ms})$. Bar $1 \mu \mathrm{m}$. c Peripheral fibers in contact with epidermis $(e p)$ and collared sensory receptor $(c r)$. Bar $1 \mu \mathrm{m}$. d Synapse (arrow) between a peripheral neurite (pf) and muscle process (ms). Bar $0.5 \mu \mathrm{m}$

vesicles are located in the basal cytoplasm. These receptors seem to be restricted to the head (Fig. 9b; violet).

Collared (type II) receptors with granular body This type of receptor cell, which is by far the most common type (50\%) is characterized by the presence of one long central single cilium surrounded by six microvilli. Instead of the rootlet, this receptor type contains a different kind of cytoplasmic specialization, called granular body, underneath the cilium (Fig. 9d). Of the six microvilli, two are located centrally adjacent to the cilium; the others are located more peripherally. The two central microvilli are extended by bundles of microfilaments which pass through the granular body (Fig. 9d, arrow). Collared receptors with granular bodies are regularly distributed along the nerve cords (Fig. 9b, in orange). In fact, each nerve cord, including the short and thin anterior branch of the ventral cord, is associated with one row (containing, in average, nine cells) of this type of receptor (Fig. 9b-d).

Collared receptors with rootlet (Fig. 9e) This type of collared receptors accounts for $16 \%$ of all sensory cells. Its cilium is anchored by a single rootlet formed by an outer striated mantle and a core of granulated material. Proximally, the rootlet is split into numerous short, longitudinal, and oblique striated elements. These receptors are mainly formed ventrally and anteriorly (Fig. 9b, in blue).

Collared receptors with obliquely radial filament bundles in the cell apex (Fig. 9f) The central cilium is flanked by two lateral microvilli from which prominent rootlets extend basally. The apical part of the receptor contains many dense-core vesicles. Unfortunately, our sections do not allow a more detailed description of the main rootlet in this ciliated receptor type. This type of sensory receptor is very rare. Only a few representatives of this sensory receptor were observed, mainly on the dorsal side (Fig. 9b, in red).

\section{Discussion}

Structure of the acoel central nervous system

Hatchlings of $S$. roscoffensis possess an anterior brain, consisting of a cortex of neuronal cell bodies surrounding a central neuropile. The brain is generally similar to that described for C. (Symsagittifera) schultzii (Delage 1886) and also resembles the juvenile brain of the macrostomid M. lignano (Morris et al. 2007), although there are some notable differences. The macrostomid brain does not have a central statocyst. The neuropile forms a single crescentshaped structure crossing the midline. Commissures form a dorsal and a ventral system of four to six bundles each, and are all embedded in the neuropile. In addition to these transverse systems of axons, vertical and longitudinally fiber bundles subdivide the macrostomid brain neuropile into several discrete compartments. A comparable compartmentalization is not evident in the considerably smaller neuropile of $S$. roscoffensis.

In more derived neoophoran platyhelminths the brain of adults is also larger and more complex than that of acoels. In the triclads Dugesia japonica and Schmidtea mediterranea (Agata et al. 1998; Cebrià et al. 2002; Cebrià 2008; Agata 2008) the brain consists of two lobes forming a large U-shaped structure from which nine pairs of branches project to the surface of the head region (Agata 2008).

The notion by Raikova (2004) that acoels do not have a "true" compact brain which contradicts the findings of this study and other papers (e.g., Reisinger 1925; Ramachandra et al. 2000; Tyler 2001; Achatz et al. 2010) can be explained in view of the different approach taken and different stages analyzed. Raikova (2004) used antibodies against serotonin, FMRFamide and GYIRFamide to label adult specimens of Nemertodermitida and Acoela. These 


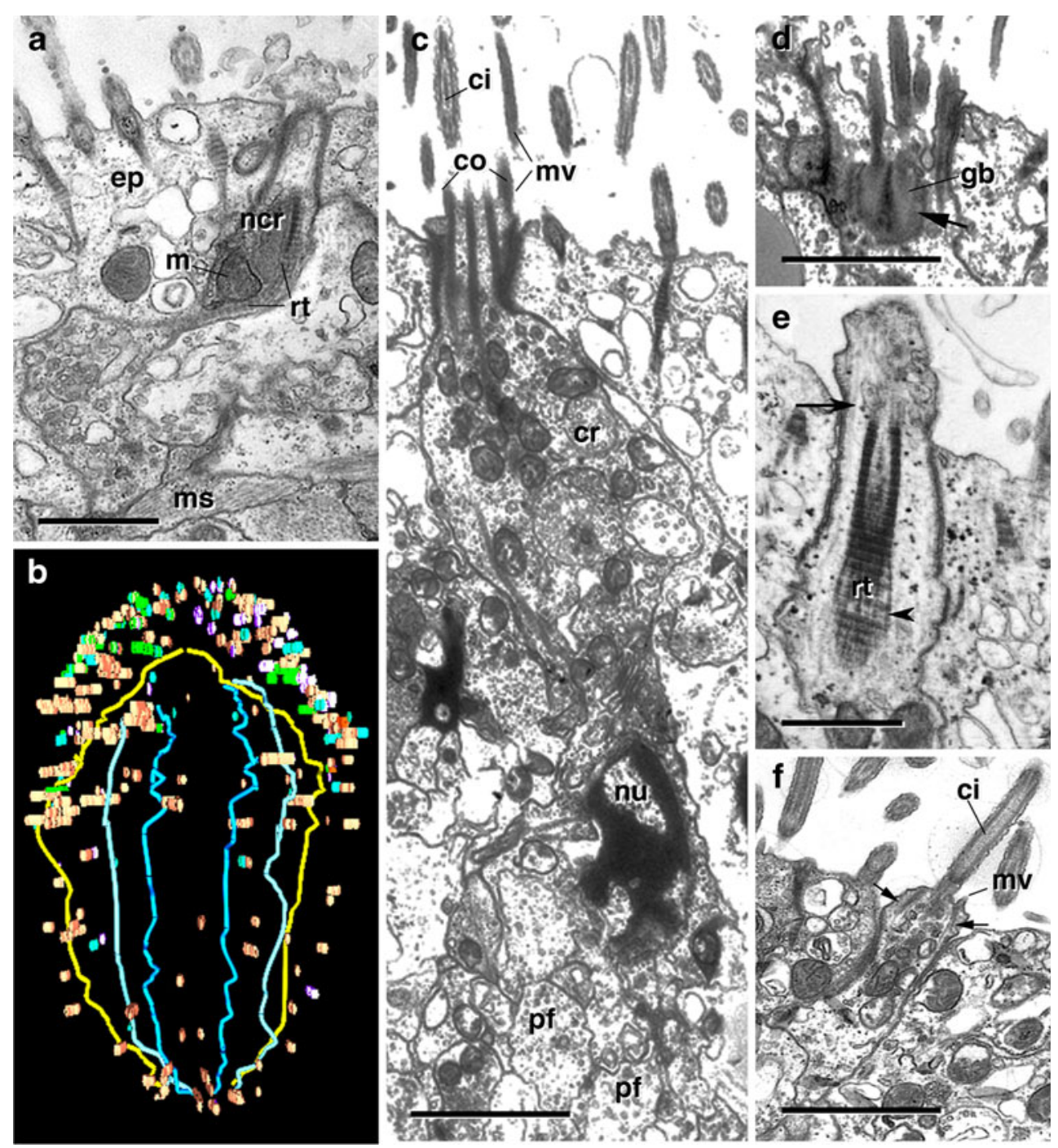

Fig. 9 The sensory receptors. a Non-collared (type I) receptors (ncr) are composed of a central cilium (out of plane of section), anchored into a rootlet $(r t)$ containing granulated material and a mitochondrion $(m)$. ep epidermal cell. Bar $0.5 \mu \mathrm{m}$. b 3D reconstruction of the nervous system in a hatchling $S$. roscoffensis, including the distribution of the different sensory cells. Dorsal view, anterior to the top. The ventral pair of nerve cord is yellow, the dorso-medial and dorso-lateral pair of nerve cords are in blue and cyan, respectively. The different types of sensory cells are represented by different colors. Non-collared (type I) receptors occurring singly are in violet, those occurring in small groups in conjunction with glands are in green; collared receptors with granular body in orange, collared receptors with basal root in blue, and collared receptors with lateral roots in red, dorsal view. c Collared receptor (type II) with granular body and no rootlet. Central cilium $(\mathrm{ci})$ is surrounded by a collar $(\mathrm{co})$ of microvilli $(\mathrm{mv})$. The microfilaments of the microvilli run from the apex to the cell body of the sensory receptor. The cell body and nucleus $(n u)$ lies underneath the muscle layer in contact with peripheral nerve fibers $(p f)$. Bar $1 \mu \mathrm{m}$. d Apical tip of collared receptor with granular body $(g b)$. The microfilaments of the two central microvilli run through the granular body (arrow), whereas the microfilaments of the peripheral microvilli pass around the periphery of the granular body. Bar $1 \mu \mathrm{m}$. e Collared receptor with basal rootlet. Note large rootlet $(r t)$ containing several longitudinal elements (arrowhead) and microfilaments extending from microvilli (arrow). Bar $0.5 \mu \mathrm{m}$. f Collared receptors lateral striated rootless. Note central cilium $(\mathrm{ci})$ and microvillar $(m v)$ collar. Note also characteristic lateral striated microfilaments (arrows) that extend basally from the microvilli. Bar $1 \mu \mathrm{m}$ markers label small subsets of neurons in the brain of most invertebrates, including various rhabditophoran flatworms (Raikova 2004; Morris et al. 2007; Cebrià 2008). For example, in acoels, as shown in the present study, the antibody against serotonin reveals one to two axons in each of the nerve cords and some of the commissures. Moreover, the location of cell bodies is all but invisible using antibodies against neurotransmitters, in particular, in case of mature nervous systems. The bulk of neuropile, surrounding the statocyst, and the surrounding cortex is not labeled by anti-serotonin or any other transmitter marker used in the literature. Finally, the relative size of the brain apparently diminishes with postembryonic development. Thus, the brain of acoel adult specimens studied by 
Raikova (2004) is very small compared to overall body size, and was dismissed as the "statocyst ganglion" (sensu Reisinger 1925). In its place, the superficial network of longitudinal nerve cords, connected by commissures, was considered as a "commissural brain". However, we would postulate that the "statocyst ganglion", which in the hatchling fills much of the anterior one third of the body and has the characteristic appearance of an invertebrate ganglion with a cortex of somata surrounding a central neuropile, represents the acoel brain.

Beyond the difference in calling the brain "statocyst ganglion", the pattern of nerve cords and commissures and the distribution of serotonergic neurons described here for S. roscoffensis is similar to that seen by Raikova (2004) and Achatz et al. (2010) in other acoel species. Thus, in hatchlings of $S$. rosocoffensis, three pairs of longitudinal nerve cords run along the animal body: two dorsal and one ventral. Each pair originates anteriorly to the statocyst as a rosette of perikarya and consists of about 50 neurites. Several commissures linking the nerve cords are regularly distributed along the tracks. This pattern also corresponds closely to that of Convoluta niphoni (Achatz et al. 2010) and Isodiametra pulcra Achatz (2007). The nervous system of $C$. niphoni and S. roscoffensis share several structures: including the paired ventral nerve cords, the neuropile surrounding the statocyst, the ventral ring of the neuropile surrounded by a loose cellular cortex, the dorsal nerve cords that do not merge together in their anterior region, the transverse connections between the lateral (outer), and the medial (inner) dorsal nerve cords. A neuropile surrounding the statocyst is also present in I. pulchra that is not closely related to $S$. roscoffensis. The anterior commissural ring revealed by the 5-HT antibody has been detected in other members of the Acoela (Actinoposthiidae, Childiidae) and in Nemertodermatida (Nemertoderma westbladi and Flagellophora apelti), prompting Raikova (2004) to suggest that this ring is an ancestral character of the nervous system for the Acoela (or Acoelomorpha if we accept its monophyly; Hejnol et al. 2009). The three pairs of frontal branches containing serotonergic fibers are reminiscent of the socalled "anterior nerve fibers" described in $N$. westbladi (Nemertodermatida) and also of the so-called "sensory cells" present in Avagina incola (Acoela, Isodiametridae) and Childia groenlandica (Acoela, Childiidae) (Raikova 2004). Finally, the anterior clusters of serotonergic cell bodies, which are located on the lateral side of commissure c2 in $S$. roscoffensis, are similar to those revealed by the anti-GYIRF antibody in $A$. incola (Acoela, Isodiametridae).

Neurons, neurites, and synapses

Neuronal types can be classified using different criteria. Among others, the vesicular content has been used to distinguish neurons in many animal systems (Bedini and Lanfranchi 1991; Biserova et al. 2000; Reuter and Halton 2001). The three most common types of vesicles (sv, dcv, and $\mathrm{lv}$ ) found in the nervous system of all phyla (e.g., Platyhelminths, Arthropoda, Vertebrata) are also found in $S$. roscoffensis. The presence of these vesicles in neurons is not mutually exclusive. Indeed in S. roscoffensis (Fig. 3d), as well as in Amphilinea foliacea (Platyhelminthes, Polycladida; Biserova et al. 2000), both sv and $\mathrm{dcv}$ can be distinguished in the same neuronal processes. However, in comparison to $C$. (S) psammophila, a well-described species, the hatchling $S$. roscoffensis is missing one neuronal type, the third neuronal type of $C$. (S.) psammophila, which is characterized by large vesicles (Bedini and Lanfranchi 1991). We cannot rule out the possibility that this type will develop later during the development or alternatively that it has been lost during evolution of the genus Symsagittifera.

The existence of glia-like cells with lamelliform, electron-dense processes is unusual for flatworms (Bedini and Lanfranchi 1991). Cells with some attributes of glia were reported in several ultrastructural studies of parasitic flatworms (Biserova et al. 2000) and of a few acoel species (Bedini and Lanfranchi 1991), where the glia-like cells are characterized by a spherical nucleus surrounded by a narrow cytoplasmic sheet provided with very few organelles, and some of its attenuated cytoplasmic projections extend into the surrounding nervous tissue. In contrast, in vertebrates and "higher" invertebrates (e.g., arthropods, annelids, molluscs), glial sheaths form envelopes around peripheral nerves, central axon bundles, or neuronal somata. The glia-like cells shown here in S. roscoffensis, when considering morphology, come closest to "true" glial cells as they exist in "higher phyla". Even though the glialike cells do not form complete sheaths around the central neuropile or nerve cords, their lamelliform processes are extensive and they may well isolate some of the bundles of axons from each other or from other elements of the neuropile/nerve cords.

Asymmetric and symmetric synapses in the hatchlings of S. roscoffensis establish contact between the different neurons forming the central nervous system, nerve cords, and the peripheral nervous plexus. In the classical electron microscopy literature, asymmetric synapses are typically excitatory and associated with small clear synaptic vesicles. Symmetric synapses contain pleomorphic vesicles of more irregular shape and different sizes and have been linked to inhibitory transmission. However, combined physiological and structural work is required to arrive at firm conclusions in regard to correlations between function and morphology of synapses in the acoel nervous system.

A specific asymmetric synapse, the ribbon type, is observed in the central nervous system. This synaptic 
element is characteristic of "more advanced" invertebrate phyla (e.g., arthropods), where it appears to function as a specialized organelle involved in docking of synaptic vesicles (Schmitz 2009). Synaptic ribbons have been previously reported for otoplanid (Bedini and Lanfranchi 1991), suggesting the ancient origin of this structure.

Cells with structural characteristics of neoblasts

Neoblasts represent a unique system of totipotent stem cells that exist throughout the lifetime of adult flatworms, both Rhabditophora and Acoela. Neoblasts are able to associate with all organs and differentiate into the corresponding cell types. In Acoela, the presence of neoblasts has already been shown in Convolutriloba longifissura (Gschwentner et al. 2001) and Isodiametra pulchra (De Mulder et al. 2009). Neoblasts have a high nucleocytoplasmic ratio, few mitochondria and free ribosomes, and the nucleus consists of uncondensed chromatin with few smaller clumps of condensed chromatin. The neoblasts are located in the peripheral parenchyma. Cells with these properties are common in our electron microscopic material. As in $I$. pulchra, the neoblast-like cells of $S$. roscoffensis are located along the lateral side of the animal; fewer cells were present closer to the midline and almost absent anterior to the statocyst. Unlike I. pulchra, in S. roscoffensis, a cluster of neoblast-like cells are clustered posterior to the brain. Neoblasts are crucial for tissue homeostasis, development, and regeneration (De Mulder et al. 2009), as well as fission, as shown in C. longifissura (Acoela, Sagittiferidae; Gaerber et al. 2007). After fission (asexual reproduction), the nervous system in C. longifissura is reorganized and develops new neurons lying alongside the in-growing nerve cords, from which axons start to grow posteriorly. $S$. roscoffensis does not reproduce by fission. Besides $S$. roscoffensis is not able to regenerate a new head, as $I$. pulchra (De Mulder et al. 2009). However, after posterior amputation of the body, the animals are able to regenerate the lost body part and recover their initial size (A. Bery, unpublished data). The classical experiments of Hanson (1967) and the more recent work of Url (2009 bachelor's thesis) and De Mulder et al. (2009) reported a similar regeneration capacity in several members of the acoel family, Convolutidae. Thus, the presence of neoblast-like cells along the nerve cord may represent a common feature in acoels, at least in the three families Convolutidae, Isodiametridae and Sagittiferidae (including C. longifissura, I. pulchra, and S. roscoffensis).

The nerve net and sensory neurons

The nerve net in hatchlings of $S$. roscoffensis contains numerous subepidermal elements at the periphery of the musculature, as well as deep fibers associated with the musculature. It resembles the pattern described for all Acoela and Nemertodermatida (Raikova 2004), as well as rhabditophoran flatworms (Kotikova and Raikova 2008). At least four different types of sensory cells were distinguished in juvenile $S$. roscoffensis. Their concentration in the anterior part of the body suggests that the sensory receptors could play a role in the specific "searching/tasting/sniffing" behavior that is characteristic for this animal. The sensory receptors contain dense vesicles of the neurosecretory type, suggesting that sensory cells produce and release peptides. Similar vesicles have been reported in S. psammophila (Bedini et al. 1973), where vesicles are concentrated in sites of contact between the basal membrane of the receptor cells and neurites of the subepidermal plexus.

Non-collared receptors with a hollow ciliary rootlet containing a granulated core (type I in Bedini et al. 1973; type 3 in Todt and Tyler 2007) are common in the genus Symsagittifera. They are similar to the Ct1 receptor described in Convoluta thela. In both Symsagittifera and Convoluta these receptors often occur in clusters of four to eight cells. The same has been reported for various species of the rhabditophoran clade Macrostomida, where noncollared receptors occur in groups and are typically associated with glandular cells, whereas collared receptors are singlets and are not directly adjacent to glands (Xylander et al. 1997).

The collared receptors without rootlet (type II in Bedini et al. 1973; type 5 in Todt and Tyler 2007) have been described in I. pulchra (Acoela, Isodiametridae) (Pfistermüller and Tyler 2002), Proporus bermudensis (Acoela, Proporidae; P3 receptor), Convoluta convoluta (Acoela, Convolutidae; Cc3 receptor), and C. thela (Acoela, Convolutidae) (Ct3 receptor; Todt and Tyler 2007). In these species, the microvilli of the collar, which encircle the sensory cilium, are thick, straight, and heavily reinforced with microfilaments. A granular body replaces the striated rootlet. Although the general morphology of these receptors is similar, a few differences can be detected between species, mainly in the number of peripheral microvilli forming the collar, and the connection of central microvilli to the granular body (Pfistermüller and Tyler 2002). Outside the Acoela, collared receptors with granular bodies (also called tubular bodies) have been reported for rhabditophorans (e.g., Microstomum; Rieger et al. 1991), cnidarians (Holtmann and Thurm 2001) and ctenophores (Tamm and Tamm 1991). In the latter phylum, these receptors are termed actin pegs cilia and they are assumed to have chemosensory and/or mechanosensory functions.

The collared receptors with obliquely radial filament bundles in the cell apex (type 4 in Todt and Tyler 2007) are very common among Acoela; they were reported in nine of 
the 13 families studied by Todt and Tyler (2007), including $C$. convoluta and $C$. thela. In the latter species, these collared receptors bear obliquely radial filament bundles in the cell apex and a single hollow ciliary rootlet, which is composed of numerous strand-like elements. Unfortunately, our sections do not allow for a fine description of the main rootlet of this ciliated receptor type.

\section{Conclusion}

Our data indicate that the juvenile acoel central nervous system, at the light and ultrastructural level, shows all the hallmarks of an invertebrate ganglion, similar to what has been described for Rhabditophora and juvenile forms of other invertebrate taxa. In other words, our data do not support the assertion made in several previous papers that Acoela differ from rhabditophoran flatworms in terms of qualitative features of their central nervous system. Thus, hatchlings of $S$. roscoffensis possess a brain that is structured like a typical invertebrate ganglion, similar to what has been described for Rhabditophora and juvenile forms of other invertebrate taxa. It is of course well possible that the shape and connectivity of individual neurons in acoles show characteristic features that would set them apart from other flatworms; the availability of specific markers in the near future will help to settle this issue.

Acknowledgments $\mathrm{AB}$ received an $\mathrm{EC}$ fellowship within the MOLMORPH network under the 6th Framework Programme "Marie Curie Host Fellowships for Early Stage Research Training (EST) (contract number MEST-CT-2005 - 020542)." We thank M. Ciluffo (UCLA) for sectioning and preparing the blocks for electron microscopy. The acquisition of images was carried out with the help of $\mathrm{M}$. Ciluffo, M. de Miguel-Bonet, and scientific personnel at the Confocal microscopy facility, UB Finally, we thank A. Wanninger, O. Raikova, and P. Ladurner, and their departmental colleagues, for commenting on the study and sharing their knowledge of acoel morphology.

Open Access This article is distributed under the terms of the Creative Commons Attribution Noncommercial License which permits any noncommercial use, distribution, and reproduction in any medium, provided the original author(s) and source are credited.

\section{References}

Achatz JG (2005) The phylogeny of the Sagittiferidae: a molecular and morphological approach. Diploma, Universty of Innsbruck

Achatz JG (2007) Embryonic development of the nervous system in Isodiametra pulchra aAcoela, Acoelomorpha. AMS Fall Newsletter 7-9

Achatz JG, Hooge M, Wallberg A, Jondelius U, Tyler S (2010) Systematic revision of acoels with $9+0$ sperm ultrastructure (Convolutida) and the influence of sexual conflict on morphology. J Zool Syst Evol Res 48(1):9-32
Agata K (2008) Planarian nervous system. Scholarpedia 3(6):5558. doi:10.4249/scholarpedia.5558. http://www.scholarpedia.org/article/ Planaria nervous system.

Agata K, Watanabe K (1999) Molecular and cellular aspect of planarian regeneration. Cell Dev Bio 10:377-383

Agata K, Soejima Y, Kato K, Kobayashi C, Umesono Y, Watanabe K (1998) Structure of the planarian central nervous system (CNS) revealed by neuronal cell markers. Zool Sci 15:433-440

Bagunà J, Riutort M (2004) The dawn of bilaterian animals: the case of acoelomorphflatworms. Bioessays 26(10):1046-1057

Bedini C, Lanfranchi A (1991) The central and peripheral nervous system of Acoela (Plathelminthes). An electron microscopial study. Acta Zool (Stockholm) 72(2):101-106

Bedini C, Ferrero E, Lanfranchi A (1973) The ultrastructure of ciliary sensory cells in two turbellaria acoela. Tissue Cell 5(3):359-372

Biserova NM, Dubicheva VA, Terenina NB, Reuter M, Halton DW, Maule AG, Gustafsson MKS (2000) The nervous system of Amphilina foliacea (Platyhelminthes, Amphilinidea): An immunocytochemical, ultrastructural and spectrofluorometrical study. Parasitology 121:441-453

Bresslau E (1909) Die Entwicklung der Acoelen. Verh Dtsch Zool Ges 19:314-324

Bush LF (1981) Marina flora and fauna of the northeastern United States. Turbellarian: Acoela Nemertodermatida. NOAA Tech Rep NMFS CIRC 440:1-8

Cardona A, Larsen C, Hartenstein V (2010a) Neuronal fiber tracts connecting the brain and ventral nerve cord of the early Drosophila larva. J Comp Neurol 515(4):427-440. doi:10.1002/cne.22086

Cardona A, Saalfeld S, Tomancak P, Hartenstein V (2010b) Drosophila brain development: closing the gap between a macroarchitectural and microarchitectural approach. Cold Spring Harbor Symp Quant Biol (in press)

Cebrià F (2008) Organisation of the nervous system in the model planarian Schmidtea mediterranea: an immunocytochemical study. Neurosci Res 61:375-384

Cebrià F, Kudome T, Nakazawa M, Mineta K, Ikeo K, Gojobori T, Agata K (2002) The expression of neural-specific genes reveals the structural and molecular complexity of the planarian central nervous system. Mech Dev 116:199-204

Colonnier M (1968) Synaptic pattern on different cell types in the different laminae of the cat visual cortex. An electron microscope study. Brain Res 9(2):268-87

Delage Y (1886) Etudes histologiques sur les planaires rhabdocoeles acoeles (Convoluta schultzii O. Sch.). Arch Zool Exp Gén 4:109144

Falck B (1962) Observations on the possibilities for cellular localization of monoamines with a fluorescence method. Acta Physiol Scand 56(197):1-2

Furness JB (1970) An examination of nerve-mediated, hyoscine-resistant excitation of the guinea pig colon. J Physiol Lond 207:803-822

De Mulder K, Kuales G, Pfister D, Willems M, Egger B, Salvenmoser W, Thaler M, Gorny A-K, Hrouda M, Borgonie G, Ladurner P (2009) Characterization of the stem cell system of the acoel Isodiametra pulchra. BMC Dev Bilogy 8:69

Gaerber CW, Salvenmoser W, Rieger RM, Gschwentner R (2007) The nervous system of Convolutriloba (Acoela) and its patterning during regeneration after asexual reproduction. Zoomorphology 126:73-87

Grimmelikhuijzen CJ, Williamson M, Hansen GN (2002) Neuropeptides in cnidarians. Can J Zool 80:1690-1702

Gschwentner R, Ladurner P, Nimeth K, Rieger R (2001) Stem cells in a basal bialterian: $\mathrm{S}$ phase and mitotic cells in Convolutriloba longifissura (Acoela, Platyhelminthes). Cell Tissue Res 304:401408

Halanych KM (2004) The new view of animal phylogeny. Annu Rev Ecol Evol Syst 35:229-256 
Hanson ED (1967) Regeneration in Acoelous Flatworms: the role of the peripheral parenchyma. Roux's Arch Entwicklungsmechanik 159:298-313

Haszprunar G (1996) Plathelminthes and Plathelminthomorphaparaphyletic taxa. J Zoolog Syst Evol Res 34:41-48

Hejnol A, Martindale MQ (2008) Acoel development indicates the independent evolution of the bilaterian mouth and anus. Letters Nature 456(20):382-387

Hejnol A, Obst M, Stamatakis A, Ott M, Rouse GW, Edgecombe GD, Martinez $\mathrm{P}$, Baguñà $\mathrm{J}$, Bailly $\mathrm{X}$, Jondelius $\mathrm{U}$, Wiens $\mathrm{M}$, Müller WE, Seaver E, Wheeler WC, Martindale MQ, Giribet G, Dunn CW (2009) Assessing the root of bilaterian animals with scalable phylogenomic methods. Proc Biol Sci 276(1677):4261-70

Holland ND (2003) Early central nervous system evolution: an era of skin brains? Nat Rev Neurosci 4(8):617-627

Holtmann M, Thurm U (2001) Variations of concentric hair cells in a cnidarian sensory epithelium (Coryne tubulosa). J Comp Neurol 432:550-563

Hooge MD (2001) Evolution of body-wall musculature in the Platyhelminthes (Acoelomorpha, Catenulida, Rhabditophora). J Morphol 249(3):171-194

Hooge MD, Tyler S (2003) Two new acoels (Acoela, Plathelminthes) from the central coast of California. Zootaxa 131:1-14

Hooge MD, Tyler S (2006) Concordance of molecular and morphological data: the example of the Acoela. Integr Comp Biol Adv Access 46(2):118-124

Hyman L (1951) The invertebrates: Platyhelminthes and Rhyanchocoela, the acoelomate Bilateria. McGraw-Hill Book Company Inc, New York

Keeble F (1910) Plant-animals a study in symbiosis. University Press, Cambridge

Kostenko AG, Mankaev YV (1990) The place of green convoluts in the system of Acoela, Turbellaria. 1. Simsagittifera ge. N Zool Zhurn Moscow 69(6):11-21

Kotikova EA, Raikova OI (2008) Architectonics of the central nervous system of Acoela, Plathelminthes, and Rotifera. J Evol Biochem Physiol 44(1):108

Ladurner P, Rieger R, Baguñà J (2000) Spatial distribution and differentiation potential of stem cells in hatchlings and adults in the marine platyhelminth Macrostomum sp.: a bromodeoxyuridine analysis. Dev Biol 226:231-241

Larsen C, Shy D, Spindler S, Fung S, Younossi-Hartenstein A, Hartenstein V (2009) Patterns of growth, axonal extension and axonal arborization of neuronal lineages in the developing Drosophila brain. Dev Biol 335:289-304

Morris J, Cardona A, De Miguel-Bonet MDM, Hartenstein V (2007) Neurobiology of the basal platyhelminth Macrostomum lignano: map and digital 3D model of the juvenile brain neuropile. Dev Genes Evol 217:569-584

Peter A (2008) The fine structure of synapses. International Brain Research Organization http://www.ibro.info/Pub/Pub_Main_Display.asp? LC Docs ID=3313. Accessed 23 March 2009

Peters A, Palay S, Webster HE (1976) The fine structure of the nervous system. Oxford University Press, New York

Pfistermüller R, Tyler S (2002) Correlation of fluorescence and electron microscopy of factin-containing sensory cells in the epidermis of Convoluta pulchra (Platyhelminthes: Acoela). Acta Zool (Stockholm) 83:15-24
Philippe H, Brinkmann H, Martinez P, Riutort M, Baguñà J (2007) Acoel flatworms are not platyhelminthes: evidence from phylogenomics. PLoS ONE 2(8):e717

Raikova OI (2004) Neuroanatomy of basal bilaterians (Xenoturbellida, Nemertodermatida, Acoela) and its phylogenetic implications. Dissertation, University of Abo

Ramachandra NB, Gates RD, Ladurner P, Jacobs DK, Hartenstein V (2000) Embryonic development in the primitive bilaterian Neochildia fusca: normal morphogenesis and isolation of POU genes Brn-1 and Brn-3. Dev Genes Evol 212(2):55-69

Reisinger E (1925) Ein landbewohnender Archiannelide. (Zugleich ein Beitrag zur Systematik der Archianneliden). Z Morphol Tiere 3:197-254

Reuter M, Halton DW (2001) Comparative neurobiology of Platyhelminthes. In: Littlewood DTJ, Bray RA (eds) Interrelationships of the Platyhelminthes. Taylor \& Francis, London

Reuter M, Raikova OI, Gustafsson MKS (1998) An endocrine brain? The pattern of FMRF-amide immunoreactivity in Acoela (Platyhelminthes). Tissue Cell 30(1):57-63

Rieger RM, Tyler S, Smith JPS, Rieger G (1991) Platyhelminthes and Nemertinea. In: Harrison FW (ed) Microscopic anatomy of Invertebrates. Wiley-Liss, New York

Ruiz-Trillo I, Riutort M, Littlewood DT, Herniou EA, Baguna J (1999) Acoel flatworms: earliest extant bilaterian Metazoans, not members of Platyhelminthes. Science 283(5409):1919-1923

Ruiz-Trillo I, Riutort M, Fourcade HM, Baguna J, Boore JL (2004) Mitochondrial genome data support the basal position of Acoelomorpha and the Polyphyly of the Platyhelminthes. Mol Phylogenet Evol 33(2):321-332

Salvini-Plawen LV (1978) On the origin of the lower Metazoa. Z Zool Systematik Evolutions Vorschag 16:40-88

Schmitz F (2009) The making of synaptic ribbons: how they are built and what they do. Neuroscientist. doi:10.1177/10738584093 40253

Sempere LF, Martinez P, Cole C, Baguñà J, Peterseon KJ (2007) Phylogenetic distribution of microRNAs supports the basal position of acoel flatworms and the phylogeny of Platyhelminthes. Evol Dev 9(5):409-415

Tamm S, Tamm S (1991) Actin pegs and ultrastructure of presumed sensory receptors of Beröe (Ctenophora). Cell Tissue Res 264:151-159

Todt C (2008) Structure and evoution of pharynx simplex in acoel flatworms (Acoela). J Morphol 270(3):271-290

Todt C, Tyler S (2007) Ciliary receptors associated with the mouth and pharynx of Acoela (Acoelomorpha): a comparative ultrastructural study. Acta Zool (Stockholm) 88:41-58

Tyler S (2001) The early worm origins and relationships of the lower flatworms. In: Littlewood DTJ, Bray R (eds) Interrelationships of the Platyhelminthes. Taylor \& Francis, London, pp 3-12

Url M (2009) The regneration capacity of the acoel flatworm Aphanostoma. Masters Thesis, University of Innsbruck

von Graff L (1891) Die Organisation der Turbellaria Acoela. Leipzig

Wallberg A, Curini-Galletti M, Ahmadzadeh A, Jondelius U (2007) Dismissal of Acoelomorpha: Acoela and Nemertodermatida are separate early bilaterian clades. Zool Scr 36(5):509-523

Xylander ER, Rohde K, Watson N (1997) Ultrastructural investigations of the sensory receptors of Macrostomum cf. bulbostylum (Plathelminthes, Macrostomida). Zool Anz 236:1-12 